\title{
Comparison of Two Strategies to Increase Serum Vitamin D Levels in a Real-World Setting: Sunlight Exposure and Oral Supplementation
}

\author{
Su Hwan $\mathrm{CHO}^{1}$, Jae Moon Yun ${ }^{1,2}$, Ji Eun LeE ${ }^{1}$, Hyejin $\mathrm{LEE}^{3}$, \\ Hee-Kyung $\mathrm{JOH}^{1,4,5}$ and Belong $\mathrm{CHO}^{1,2,6, *}$ \\ ${ }^{1}$ Department of Family Medicine, Seoul National University Hospital, Seoul, Republic of Korea \\ ${ }^{2}$ Center for Health Promotion and Optimal Aging of Seoul National University Hospital in Korea, \\ Seoul, Republic of Korea \\ ${ }^{3}$ Department of Family Medicine, Seoul National University Bundang Hospital, \\ Seongnam, Republic of Korea \\ ${ }^{4}$ Department of Medicine, Seoul National University College of Medicine, Seoul, Republic of Korea \\ ${ }^{5}$ Department of Family Medicine, Seoul National University Health Service Center, Seoul, Republic of Korea \\ ${ }^{6}$ Department of Family Medicine, Seoul National University College of Medicine, Seoul, Republic of Korea
}

(Received April 26, 2021)

\begin{abstract}
Summary Sunlight exposure and oral supplementation are the key strategies to increase serum 25-hydroxyvitamin D [25(OH)D] concentration. We aimed to determine elevation in serum 25(OH)D levels by comparing sunlight exposure and oral vitamin D supplementation in vitamin D-deficient participants who chose the treatment strategy by shared decision-making. We enrolled 197 participants aged $\geq 19 \mathrm{y}$ who had vitamin D deficiency (serum $25(\mathrm{OH}) \mathrm{D}<20 \mathrm{ng} / \mathrm{mL}$ ). Participants selected their treatment method through shared decision-making by preference: sunlight exposure or 1,000 IU oral vitamin D3 supplementation daily. Changes in serum 25(OH)D concentration and duration of sunlight exposure were evaluated after 3 mo. Among 197 participants, 26 (13\%) selected sunlight exposure and $171(87 \%)$ selected oral vitamin D supplementation. Seasonal distribution of participants and follow-up rate after 3 mo were not significantly different. There was no significant increase in mean serum 25(OH)D levels in the sunlight exposure group. Conversely, the mean serum $25(\mathrm{OH}) \mathrm{D}$ level increased by $11 \mathrm{ng} / \mathrm{mL}$ after $3 \mathrm{mo}$ in the oral vitamin $\mathrm{D}$ supplementation group. The duration of mean sunlight exposure per day during the study period was not significantly different between the groups. Oral supplementation with 1,000 IU vitamin D3 daily significantly increased serum 25(OH)D levels in vitamin Ddeficient participants after 3 mo, while sunlight exposure did not. This study suggests that oral supplementation is more effective than sun exposure in increasing vitamin D levels in the Korean population. Therefore, new recommendations on maintaining adequate vitamin D levels are needed in the Korean population.
\end{abstract}

Key Words vitamin D deficiency, sunlight exposure, oral supplementation, cholecalciferol, shared-decision making

Vitamin D deficiency may cause a decrease in bone mineral density and muscle weakness, leading to osteoporosis, falls, and fractures in adults. Moreover, a low serum vitamin D level is associated with various health problems such as cancer, cardiovascular disease, autoimmune disease, and infectious diseases $(1,2)$. A nationwide survey in South Korea reported that $47.3 \%$ of men and $64.5 \%$ of women had vitamin D deficiency and $86.8 \%$ of men and $94.3 \%$ of women had vitamin D insufficiency, which indicates a higher prevalence than that in the United States or Canada (3).

As only few foods naturally contain vitamin $\mathrm{D}$, the major source of vitamin $D$ for most people is the synthesis in the skin by exposure to ultraviolet B (UVB) in sunlight (1). However, the synthesis of vitamin D due to

\footnotetext{
*To whom correspondence should be addressed.

E-mail: belong@snu.ac.kr
}

sunlight exposure is affected by the individual's genetic composition, skin pigmentation, lifestyle including lack of outdoor activities during the daytime or use of sunscreen, occupation, and environmental factors including seasonal variation, latitude, or air pollution (4). Previous studies have recommended that vitamin D synthesis occurs upon exposure to sunlight for 5-30 min a day (5), but its effectiveness remains unclear, especially in Asian populations. It may be difficult to maintain adequate levels of vitamin $\mathrm{D}$ only by changing lifestyle (6); therefore, supplementation of vitamin D can be an alternative choice to achieve a threshold of sufficient serum 25-hydroxyvitamin D [25(OH)D] level (7).

In shared decision-making, the clinician and the patient share their preference for treatment and reach a consensus on treatment choice (8). It is well known that shared decision-making with appropriate information can ameliorate treatment adherence, patient satis- 
Table 1. Basal characteristics of study population.

\begin{tabular}{|c|c|c|c|}
\hline & $\begin{array}{l}\text { Sunlight exposure group } \\
\qquad(n=26)\end{array}$ & $\begin{array}{l}\text { Oral vitamin D supplementation group } \\
\qquad(n=171)\end{array}$ & $p$-value \\
\hline Age & $62(7.8)$ & $61(8.1)$ & 0.48 \\
\hline Female & $10(39)$ & $81(47)$ & 0.40 \\
\hline Enrollment season & & & 0.32 \\
\hline Spring & $3(12)$ & $24(14)$ & \\
\hline Summer & $4(15)$ & $15(8)$ & \\
\hline Autumn & $13(50)$ & $66(39)$ & \\
\hline Winter & $6(23)$ & $66(39)$ & \\
\hline Smoking & & & 0.73 \\
\hline None & $14(54)$ & $88(52)$ & \\
\hline Past & $10(38)$ & $58(34)$ & \\
\hline Current & $2(8)$ & $19(11)$ & \\
\hline No response & $0(0)$ & $6(3)$ & \\
\hline Drinking & & & 0.69 \\
\hline None & $12(46)$ & $83(49)$ & \\
\hline Past & $0(0)$ & $2(1)$ & \\
\hline Current & $14(54)$ & $80(47)$ & \\
\hline No response & $0(0)$ & $6(3)$ & \\
\hline Regular Exercise & & & 0.54 \\
\hline No & $6(23)$ & $57(34)$ & \\
\hline Yes & $19(73)$ & $105(62)$ & \\
\hline No response & $1(4)$ & $7(4)$ & \\
\hline Body mass index & $24(2.1)$ & $24(3.5)$ & 0.94 \\
\hline Waist circumference & $85(5.2)$ & $85(11.3)$ & 0.98 \\
\hline Systolic blood pressure & $127(15.7)$ & $126(14.7)$ & 0.83 \\
\hline Diastolic blood pressure & $76(9.4)$ & $75(11.2)$ & 0.69 \\
\hline Body fat percent & $26(5.6)$ & $26(5.6)$ & 0.92 \\
\hline Initial vitamin D & $16(2.3)$ & $16(3.4)$ & 0.79 \\
\hline Fasting blood glucose & $97(18.2)$ & $102(24.1)$ & 0.33 \\
\hline $\mathrm{HbA1C}$ & $5.8(0.4)$ & $5.8(0.7)$ & 0.67 \\
\hline AST & $24(7.5)$ & $27(12.6)$ & 0.18 \\
\hline ALT & $25(13.9)$ & $28(19)$ & 0.42 \\
\hline Total bilirubin & $1.2(0.5)$ & $1.2(1.6)$ & 0.99 \\
\hline GGT & $39(31)$ & $44(60.5)$ & 0.64 \\
\hline Total cholesterol & $203(45.9)$ & $186(43.2)$ & 0.06 \\
\hline Triglyceride & $109(49.2)$ & $115(68.6)$ & 0.69 \\
\hline HDL-C & $58(14.5)$ & $57(17)$ & 0.76 \\
\hline LDL-C & $129(43.9)$ & $110(38.7)$ & 0.02 \\
\hline
\end{tabular}

Data are presented as the means with standard deviations for continuous variables and numbers with percentages for categorical variables; $p<0.05$ is statistically significant; HbA1C: hemoglobin A1C; AST: aspartate transaminase; ALT: alanine transaminase; GGT: gamma-glutamyltransferase; HDL-C: high-density lipoprotein cholesterol; LDL-C: low-density lipoprotein cholesterol.

faction, and quality of life (9). These improvements are noticeable particularly for chronic conditions that require prevention, constant dosing, or lifestyle modification, which are difficult to maintain consistently in the real world (10). Several trials have assessed the potential of UVB in synthesizing an adequate amount of vitamin $\mathrm{D}(11,12)$ or the requirement of oral vitamin D supplementation $(13,14)$, while only few studies have compared sunlight exposure to oral vitamin D supplementation directly, especially in Asian populations. In this trial, we aimed to determine the elevation in serum 25(OH)D levels by two strategies, namely, sunlight exposure and oral vitamin D supplementation, directly in patients with vitamin D deficiency. Moreover, this study also aimed to evaluate participants' preferences for treatment strategy by shared decision-making and the effect of treatment accordingly in real-world settings.

\section{METHODS}

This prospective, non-randomized, comparative clinical trial was conducted at the Center for Health Promo- 
Table 2. Differences in serum 25-hydroxyvitamin D levels by season of enrollment.

\begin{tabular}{|c|c|c|c|c|c|c|c|c|c|}
\hline & \multicolumn{4}{|c|}{ Sunlight exposure group } & \multicolumn{4}{|c|}{ Oral vitamin D supplementation group } & \multirow{2}{*}{$\begin{array}{c}p \text {-value } \\
\text { compared } \\
\text { between } \\
\text { groups }\end{array}$} \\
\hline & Baseline & At $3 \mathrm{mo}$ & $\begin{array}{c}\text { Mean } \\
\text { difference }\end{array}$ & $p$-value & Baseline & At $3 \mathrm{mo}$ & $\begin{array}{c}\text { Mean } \\
\text { difference }\end{array}$ & $p$-value & \\
\hline All & $16(2.3)$ & $18(5.6)$ & $2(4.5)$ & 0.08 & $16(3.4)$ & $27(7.8)$ & $11(8.5)$ & $<0.01$ & $<0.01$ \\
\hline $\begin{array}{l}\text { Spring } \\
\text { (March- } \\
\text { May) }\end{array}$ & $15(4.0)$ & $18(6.0)$ & $3(3.5)$ & 0.27 & $16(3.1)$ & $28(9.5)$ & $12(10.4)$ & $<0.01$ & 0.14 \\
\hline $\begin{array}{l}\text { Summer } \\
\text { (June- } \\
\text { August) }\end{array}$ & $16(1.7)$ & $24(3.8)$ & $8(5.9)$ & 0.30 & $16(4.3)$ & $23(7.0)$ & $6(6.6)$ & 0.01 & 0.73 \\
\hline $\begin{array}{l}\text { Autumn } \\
\text { (September- } \\
\text { November) }\end{array}$ & $16(2.2)$ & $16(6.5)$ & $0(4.6)$ & 0.85 & $15(3.2)$ & $26(8.0)$ & $11(8.1)$ & $<0.01$ & $<0.01$ \\
\hline $\begin{array}{l}\text { Winter } \\
\text { (December- } \\
\text { February) }\end{array}$ & $16(2.2)$ & $18(1.6)$ & $2(2.1)$ & 0.18 & $15(3.5)$ & $28(6.7)$ & $13(7.9)$ & $<0.01$ & 0.01 \\
\hline
\end{tabular}

Data are presented as the means with standard deviations; $p<0.05$ is statistically significant.

tion and Optimal Aging, Seoul National University Hospital, Korea.

Study population. We enrolled 197 participants aged $\geq 19$ y who were diagnosed with vitamin D deficiency (serum 25(OH)D $<20 \mathrm{ng} / \mathrm{mL}$ ) during health screening between September 2014 and February 2016. We excluded participants who had taken vitamin D supplements and met any of the following exclusion criteria: pregnancy, history of liver disease or renal disease including kidney stone, and hypercalcemia.

Trial procedures. On the day of visit to check the health screening results, participants who were diagnosed with vitamin D deficiency selected one of the two treatment methods after receiving an one-on-one explanation from the researchers by shared decision-making on preference: sunlight exposure or oral vitamin D supplementation. Participants in the sunlight exposure group were instructed to undergo sunlight exposure from 10 a.m. to 3 p.m., as the amount of ultraviolet light was sufficient at this time. Duration of exposure to sunlight was guided differently by season: expose hands, arms, and neck for 30 min to an hour in the winter and expose arms and legs by wearing shorts for approximately 10 min without sunscreen in the summer. Participants in the oral vitamin D supplementation group were instructed to take a pill (vitamin D3 1,000 IU) every day. The results of health screening were used as baseline tests, and changes in serum 25(OH)D concentration were evaluated after 3 mo. The medical staff provided information about the treatment choice but were not directly involved in the selection of treatment methods.

Measurements. Data of sociodemographic characteristics, past medical history including medication, anthropometric data, and blood pressure were collected at baseline. Information about smoking, drinking, physical activity, and habits related to sunlight exposure was obtained by self-report. Data of the following laboratory parameters were collected at baseline: 25-hydroxyvitamin D, fasting blood glucose, hemoglobin A1c, aspartate transaminase (AST), alanine transaminase (ALT), bilirubin, gamma-glutamyltransferase, total cholesterol, low-density lipoprotein cholesterol (LDL-C), high-density lipoprotein cholesterol (HDL-C), triglyceride, creatinine, blood urea nitrogen, and calcium. After 3 mo, serum 25(OH)D levels were measured and compared with baseline data. Duration of sunlight exposure for 3 mo was self-reported using a questionnaire that measuring the average time per day spent being exposed to sunlight.

Statistical analysis. All statistical analyses were performed using STATA MP statistical software, version 14.1 (Stata Corp., College Station, TX, USA). $t$-test, chisquare test, and Fisher's exact test were used for continuous variables or categorical variables to compare mean values of clinical laboratory results and percentages of sociodemographic characteristics between the sunlight exposure group and oral the vitamin D supplementation group. Paired $t$-test was used to compare changes in serum 25(OH)D levels in each treatment group. Duration of sunlight exposure after 3 mo was compared between the two groups using $t$-test. A multivariable linear regression analysis was performed to adjust differences in sunlight exposure according to calendar months. $p<0.05$ was considered to indicate statistical significance.

Ethics statement. The trial was approved by the Institutional Review Board of Seoul National University 


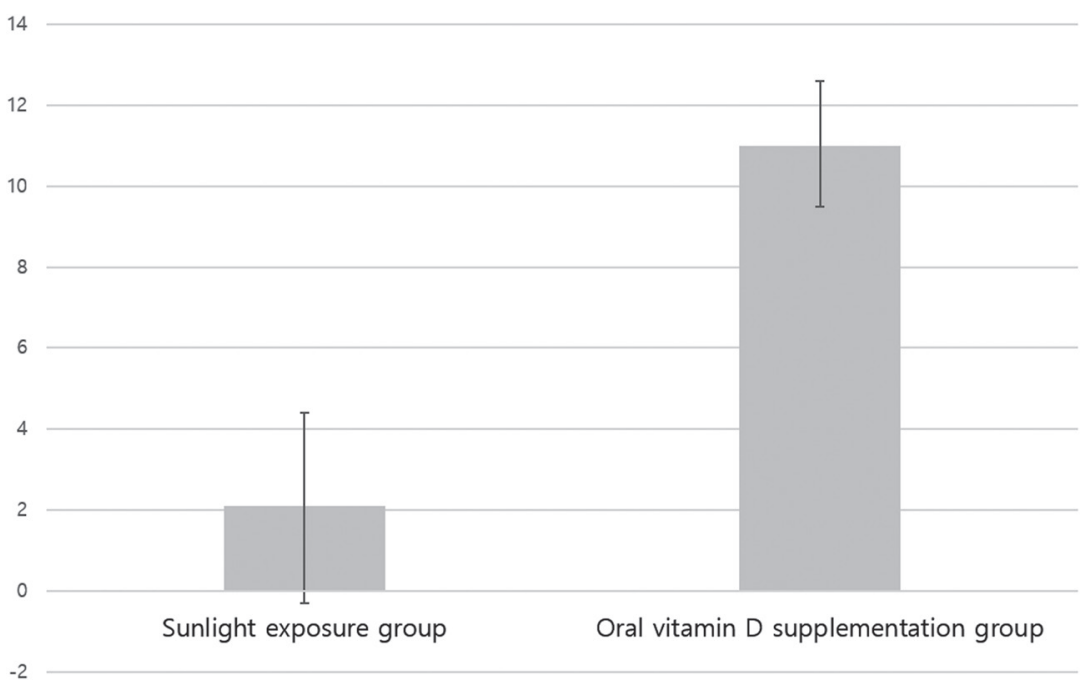

Fig. 1. Comparison of mean change in serum 25-hydroxyvitamin D $(25(\mathrm{OH}) \mathrm{D})$ levels for 3 mo according to treatment strategies. There was no significant increase in mean serum 25(OH)D levels in the sunlight exposure group. Conversely, the mean serum 25(OH)D level increased by $11 \mathrm{ng} / \mathrm{mL}$ after $3 \mathrm{mo}$ in the oral vitamin D supplementation group $(p<0.01)$.

Table 3. Sunlight exposure duration.

\begin{tabular}{|c|c|c|c|}
\hline & Sunlight exposure group & Oral vitamin D supplementation group & $p$-value \\
\hline \multicolumn{4}{|l|}{ Initial sunlight duration } \\
\hline Time per day & $76(83.2)$ & $59(95.6)$ & 0.57 \\
\hline Peak time per day (10 a.m. to 3 p.m.) & $58(59.2)$ & $40(65.2)$ & 0.36 \\
\hline \multicolumn{4}{|l|}{ Follow sunlight duration } \\
\hline Time per day & $53(60.6)$ & $55(77.0)$ & 0.93 \\
\hline Peak time per day (10 a.m. to 3 p.m.) & $48(59.3)$ & $40(60.4)$ & 0.64 \\
\hline \multicolumn{4}{|l|}{ Difference of sunlight exposure } \\
\hline Time per day & $-23(108.8)$ & $-4(72.8)$ & 0.46 \\
\hline Peak time per day (10 a.m. to 3 p.m.) & $-10(89.7)$ & $0(49.3)$ & 0.59 \\
\hline
\end{tabular}

Data are presented as the means with standard deviations; $p<0.05$ is statistically significant.

Hospital (IRB No. H-1404-137-574) and was carried out in compliance with the Declaration of Helsinki. Informed consent was obtained from all participants in written form before enrollment.

\section{RESULTS}

\section{Baseline characteristics}

The characteristics of the study population are shown in Table 1. Among 197 participants, 26 (13\%) selected sunlight exposure and $171(87 \%)$ selected oral vitamin D supplementation. There were no significant differences between the sunlight exposure group and the oral vitamin D supplementation group in all variables except for LDL-C. The seasonal distribution of the participants in the two groups was also not significantly different.

Mean change in serum 25-hydroxyvitamin D levels

After 3 mo of treatment for vitamin D deficiency, a total of 133 participants $(68 \%)$ had the follow-up visit. Of them, 17 (65\%) were in the sunlight exposure group and $116(68 \%)$ were in the oral vitamin D supplemen- tation group, with no significant difference in follow-up rate. Mean serum 25(OH)D levels in the sunlight exposure and oral vitamin $\mathrm{D}$ supplementation groups after $3 \mathrm{mo}$ were $18 \mathrm{ng} / \mathrm{mL}$ and $27 \mathrm{ng} / \mathrm{mL}$, respectively. There was no significant increase in mean serum $25(\mathrm{OH}) \mathrm{D}$ levels in the sunlight exposure group in any season (Table 2). Conversely, the mean serum 25(OH)D level in the oral vitamin D supplementation group increased by $11 \mathrm{ng} / \mathrm{mL}$ after $3 \mathrm{mo}$ (Fig. 1), and this significant increase occurred in all seasons. The differences in serum 25(OH)D levels between the two groups was significant when adjusted for each calendar month $(p<$ 0.01). The rates of vitamin D deficiency in the sunlight exposure group and the oral vitamin D supplementation group at the follow-up visit were $65 \%$ and $19 \%$, respectively, and there was a significant difference between the two groups.

Sunlight exposure duration. Mean duration of sunlight exposure per day during the study period, which was determined using self-questionnaire at follow-up visit, was $53 \mathrm{~min}$ in sunlight exposure group and $55 \mathrm{~min}$ in 
oral supplementation group, and there was no significant difference between the groups (Table 3). Similarly, there was no significant difference in peak time (10 a.m. to 3 p.m.) of sunlight exposure during the 3 mo. The non-response rate was not significantly different between the two groups at the follow-up visit $(p=0.25)$.

\section{DISCUSSION}

The majority of the participants $(87 \%)$ preferred oral supplementation over sunlight exposure as the treatment method for vitamin D deficiency. Sociocultural factors and lifestyle may have influenced the tendency of this choice. South Korea is still one of the countries with the longest working hours among OECD countries (15); hence, the difficulty in taking the time to expose oneself to sunlight during the daytime may have prompted the preference for oral supplementation. Additionally, Koreans usually prefer to avoid sun exposure and take protective measures including applying sunscreens, covering most parts of bodies with clothes, using an umbrella, and staying in the shade when outdoors because fair skin is considered beautiful (16). For these reasons, participants may have preferred taking one pill daily than sunlight exposure in real-world circumstances.

The simple strategy for achieving adequate vitamin D through sunlight exposure is known to involve exposure of the arms and legs to sunlight for 5-30 min between 10 a.m. and 3 p.m. twice or thrice a week (1). However, the recommendation for sunlight exposure was made for Caucasians (mostly skin type 2 or 3) (17), while Koreans have skin type 3 to 5 , which are darker (18). As melanin blocks UVB penetration into the epidermis, there is a reduction in cutaneous vitamin D production (4); hence, darker-skinned Koreans may need longer sun exposure time than light-skinned people to synthesize the same amount of vitamin D (16). In our study, the sunlight exposure group underwent sunlight exposure for $53 \mathrm{~min}$ each day on average after 3 mo, which indicates that there was sufficient sunlight exposure regardless of the season according to the guidelines. Nevertheless, sunlight exposure failed to increase serum $25(\mathrm{OH}) \mathrm{D}$ levels, and this result was consistent with studies conducted on Koreans $(19,20)$ or nonWestern immigrants (21). In a previous study, there was some increase in serum $25(\mathrm{OH}) \mathrm{D}$, but it was insufficient to prevent vitamin D deficiency even though a mobile application was used to increase compliance with sunlight exposure (19). In another study that evaluated the effect of sunlight exposure recommended in the current guidelines, there was only a slight increase of $0.9 \mathrm{ng} / \mathrm{mL}$ after $1 \mathrm{mo}$ even though the study was conducted in the summer (20). However, a study on people living in the southernmost area of South Korea showed that people who work outdoors most time of the day were not in a vitamin D-deficient state on average, and their serum 25(OH)D level was much higher than that of the general population (22). Given these results, the current recommendations for sunlight exposure to maintain a sufficient level of vitamin D may be most likely not suitable for the Korean population and a longer duration of exposure to sunlight may be required. However, considering not only the cultural aspects that involve reduced exposure to sunlight and rarely tanning but also other factors that can affect the amount of sunlight, such as lack of sunlight in the winter and due to air pollution $(4,23)$, sunlight exposure may be an inappropriate method to increase serum 25(OH)D levels among Koreans in real-world circumstances.

Vitamin D deficiency induces a decrease in the absorption of intestinal calcium and phosphorus, resulting in secondary hyperparathyroidism (1). An increase in osteoclastic activity mediated by elevated parathyroid hormone causes a decrease in bone mineral density, resulting in osteopenia and osteoporosis. Parathyroid hormone levels are inversely associated with 25(OH)D levels until 25(OH)D reaches 30-40 ng/mL, at which point, it begins to plateau $(24,25)$. The above results and the report that intestinal calcium absorption increased when serum 25(OH)D level increased from 20 to $32 \mathrm{ng} / \mathrm{mL}$ indicate that a vitamin D level of $30 \mathrm{ng} /$ $\mathrm{mL}$ or greater is considered sufficient (26). In our study, daily oral supplementation of 1,000 IU vitamin D3 for 3 mo significantly increased serum 25(OH)D levels and resolved the vitamin D-deficient state in most participants $(81 \%)$. This result is similar to that of a previous study (27). However, the results also showed that only $36 \%$ of the participants on oral supplementation achieved sufficient vitamin D levels ( $>30 \mathrm{ng} / \mathrm{mL})$. These results suggest that higher doses of vitamin D supplementation are needed, as it is known that achieving vitamin D sufficiency may minimize the risk of several types of cancer, cardiovascular disease, autoimmune disease, respiratory infection, and overall mortality (28-31). A previous meta-analysis that analyzed the effect of vitamin D supplementation on serum 25(OH)D levels showed a linear relationship between daily oral supplementation of vitamin D and serum 25(OH)D levels in a Caucasian population (32). As previously recommended by the U.S. Preventive Services Task Force and the U.S. Endocrine Society, daily oral supplementation of vitamin D higher than 1,000 IU is needed to achieve and maintain sufficient vitamin $\mathrm{D}$ levels in adults $(33,34)$. However, a previous study that analyzed 108 published estimates on vitamin D supplementation and vitamin D levels suggested that 2,909 IU of vitamin D per day is needed to achieve vitamin D sufficiency in more than $97.5 \%$ of healthy people (35). Given these results, it is necessary to consider higher doses for oral supplementation than the dose we have used to achieve optimal serum 25(OH)D levels, and further studies are needed to support this finding.

The current study has several limitations. First, this study was designed to help participants choose a treatment method that fits their lifestyle to elevate the serum $25(\mathrm{OH}) \mathrm{D}$ in real-world settings by shared decisionmaking. As a result, most of the participants chose oral supplementation, which resulted in significantly different numbers of participants in both groups. Although 
there were no differences in the baseline characteristics between the two groups, the counts of sunlight exposure group were small; thus, selection bias may have occurred. Therefore, it may be necessary to assess the difference in effectiveness between the two groups precisely through larger studies. Second, the results of the oral supplementation group might include the combined effects of sunlight exposure and oral supplementation of vitamin D because there was no significant difference in the sunlight exposure duration between the two groups. Because the two groups were given sufficient explanation equally before the participants chose a treatment regime, this could have influenced the oral supplementation group to actively undergo sunlight exposure. As a result, this study eventually made a comparison between the sunlight exposure-only group and the combined sunlight exposure and oral supplementation group, a little different from the researchers' original intention. However, considering the results of the sunlight exposure group after $3 \mathrm{mo}$, the additional effect of increasing vitamin D-related sunlight exposure may be insignificant in this real-world setting; hence, the results of this study demonstrate the effectiveness of the oral supplementation method. Third, as sun exposure duration was investigated before and after the study through a self-questionnaire, it is possible that a recall error may have occurred in this process. Additionally, because some participants did not respond to the survey conducted at the end of the study, the survey results may not reflect the overall results accurately. However, because there was no significant difference between the two groups in the non-response rate of the questionnaire $(p=0.25)$, assuming that non-respondents randomly occurred, each result can be considered to represent each group. Lastly, because our study enrolled participants throughout the year, dermal vitamin D synthesis due to sunlight exposure might not be sufficient for those enrolled in late autumn to winter at the latitude of the northern area of South Korea (33$\left.37^{\circ} \mathrm{N}\right)(4,36)$. Although it was not statistically significant because the number of participants was limited, the subgroup of sunlight exposure enrolled in summer showed the result of increased serum 25(OH)D levels. Considering this, further studies enrolling more participants in the season when the amount of sunlight is abundant, from spring to early autumn, could provide clear evidence.

This study has several strengths. To the best of our knowledge, this study is a relatively large clinical study comparing the effects between sunlight exposure and oral supplementation of vitamin D on serum $25(\mathrm{OH}) \mathrm{D}$ levels directly in the Korean population. In addition, because participants selected a treatment strategy that they could actually keep the method well by shareddecision-making, our findings might be helpful to recommend an appropriate approach for elevating serum $25(\mathrm{OH}) \mathrm{D}$ levels considering their lifestyle in the realworld clinical setting. The study duration of 3 mo is sufficient to evaluate the change in the serum $25(\mathrm{OH}) \mathrm{D}$ level; hence, the effects of the two treatment methods can be fully reflected and appreciated.

In our study, daily oral supplementation of 1,000 IU vitamin D3 significantly increased serum 25(OH)D levels in the vitamin D-deficient state after 3 mo, while sunlight exposure did not even if the sunlight exposure duration was adequate. With a daily oral supplementation dose of 1,000 IU vitamin D3, a sufficient number of participants are able to overcome vitamin D deficiency, but this dose is not enough to achieve sufficient levels. Our study suggests that oral supplementation of vitamin D3 is more effective in daily life than sun exposure to increase vitamin D levels in the Korean population, especially during autumn and winter. Given several circumstances, the synthesis of vitamin $\mathrm{D}$ due to sunlight exposure in the real-world setting seems difficult to achieve; therefore, new recommendations on maintaining adequate vitamin D levels are needed in the Korean population.

\section{Authorship}

Conceptualization: Cho B. Methodology: Lee H, Joh HK. Data curation: Lee JE, Lee H. Formal analysis: Cho SH, Yun JM. Funding acquisition: Cho B. Investigation: Cho B, Joh HK. Software: Cho SH, Yun JM. Validation: Lee JE. Writing - original draft: Cho SH, Yun JM. Writing-review \& editing: Lee JE, Lee H, Joh HK, Cho B.

Su Hwan Cho and Jae Moon Yun contributed equally to this work.

\section{Disclosure of state of COI}

The authors have no potential conflicts of interest to disclose.

\section{Funding}

DALIM BIOTECH provided oral vitamin D supplements and research funding. The study design, data collection, analysis, interpretation of the data and decision to submit for publication were accomplished independently from the funding source.

\section{REFERENCES}

1) Holick MF. 2007. Vitamin D deficiency. N Engl J Med 357(3): 266-281.

2) Holick MF, Chen TC. 2008. Vitamin D deficiency: a worldwide problem with health consequences. Am J Clin Nutr 87(4): 1080s-1086s.

3) Choi HS. 2013. Vitamin D status in Korea. Endocrinol Metab (Seoul) 28(1): 12-16.

4) Saraff V, Shaw N. 2016. Sunshine and vitamin D. Arch Dis Child 101(2): 190-192.

5) Reid IR, Gallagher DJ, Bosworth J. 1986. Prophylaxis against vitamin $\mathrm{D}$ deficiency in the elderly by regular sunlight exposure. Age Ageing 15(1): 35-40.

6) Hanley DA, Cranney A, Jones G, Whiting SJ, Leslie WD, Cole DE, Atkinson SA, Josse RG, Feldman S, Kline GA, Rosen C; Guidelines Committee of the Scientific Advisory Council of Osteoporosis Canada. 2010. Vitamin D in adult health and disease: a review and guideline statement from Osteoporosis Canada. CMAJ 182(12): E610-E618.

7) Pramyothin P, Holick MF. 2012. Vitamin D supplementation: guidelines and evidence for subclinical defi- 
ciency. Curr Opin Gastroenterol 28(2): 139-150.

8) Charles C, Whelan T, Gafni A. 1999. What do we mean by partnership in making decisions about treatment? BMJ 319(7212): 780-782.

9) Ong LM, de Haes JC, Hoos AM, Lammes FB. 1995. Doctor-patient communication: a review of the literature. Soc Sci Med 40(7): 903-918.

10) Moin T, Duru OK, Turk N, Chon JS, Frosch DL, Martin JM, Jeffers KS, Castellon-Lopez Y, Tseng CH, Norris K, Mangione CM. 2019. Effectiveness of shared decision-making for diabetes prevention: 12-month results from the Prediabetes Informed Decision and Education (PRIDE) trial. J Gen Intern Med 34(11): 2652-2659.

11) Bogh MK, Schmedes AV, Philipsen PA, Thieden E, Wulf HC. 2011. Vitamin D production depends on ultraviolet-B dose but not on dose rate: a randomized controlled trial. Exp Dermatol 20(1): 14-18.

12) Bogh MK, Schmedes AV, Philipsen PA, Thieden E, Wulf HC. 2012. A small suberythemal ultraviolet B dose every second week is sufficient to maintain summer vitamin D levels: a randomized controlled trial. $\mathrm{Br} J \mathrm{Der}$ matol 166(2): 430-433.

13) Ooms ME, Roos JC, Bezemer PD, van der Vijgh WJ, Bouter LM, Lips P. 1995. Prevention of bone loss by vitamin D supplementation in elderly women: a randomized double-blind trial. J Clin Endocrinol Metab 80(4): 1052-1058.

14) Heaney RP, Davies KM, Chen TC, Holick MF, BargerLux MJ. 2003. Human serum 25-hydroxycholecalciferol response to extended oral dosing with cholecalciferol. Am J Clin Nutr 77(1): 204-210.

15) OECD. 2019. OECD Labour Force Statistics 2019. OECD Publishing, Paris.

16) Nimitphong H, Holick MF. 2013. Vitamin D status and sun exposure in southeast Asia. Dermatoendocrinol 5(1): 34-37.

17) Fitzpatrick TB. 1988. The validity and practicality of sun-reactive skin types I through VI. Arch Dermatol 124(6): 869-871.

18) Youn JI, Choe YB, Park SB, Suh DH, Park YK, Ahn SK, Kim KH, Kim ST, Kim HY, Lee SC, Oh SJ, Kim JJ, Kang SH. 2000. The Fitzpatrick skin type in Korean people. Korean J Dermatol 38(7): 920-927.

19) Joh HK, Hwang SS, Cho B, Lim CS, Jung SE. 2020. Effect of sun exposure versus oral vitamin D supplementation on serum 25-hydroxyvitamin D concentrations in young adults: A randomized clinical trial. Clin Nutr 39(3): 727-736.

20) Lee YM, Kim SA, Lee DH. 2020. Can current recommendations on sun exposure sufficiently increase serum vitamin D level?: One-month randomized clinical trial. J Korean Med Sci 35(8): e 50.

21) Wicherts IS, Boeke AJ, van der Meer IM, van Schoor NM, Knol DL, Lips P. 2011. Sunlight exposure or vitamin D supplementation for vitamin D-deficient nonwestern immigrants: a randomized clinical trial. Osteoporos Int 22(3): 873-882.

22) Lee DH, Park KS, Cho MC. 2018. Laboratory confirmation of the effect of occupational sun exposure on serum 25-hydroxyvitamin D concentration. Medicine (Baltimore) 97(27): e11419.

23) Barrea L, Savastano S, Di Somma C, Savanelli MC, Nappi F, Albanese L, Orio F, Colao A. 2017. Low serum vitamin D-status, air pollution and obesity: A dangerous liaison. Rev Endocr Metab Disord 18(2): 207-214.

24) Carnevale V, Nieddu L, Romagnoli E, Battista C, Mascia ML, Chiodini I, Eller-Vainicher C, Frusciante V, Santini SA, La Porta M, Minisola S, Scillitani A. 2010. Regulation of PTH secretion by 25-hydroxyvitamin D and ionized calcium depends on vitamin D status: a study in a large cohort of healthy subjects. Bone 47(3): 626-630.

25) Okazaki R, Sugimoto T, Kaji H, Fujii Y, Shiraki M, Inoue D, Endo I, Okano T, Hirota T, Kurahashi I, Matsumoto T. 2011. Vitamin D insufficiency defined by serum 25hydroxyvitamin D and parathyroid hormone before and after oral vitamin $\mathrm{D}_{3}$ load in Japanese subjects. J Bone Miner Metab 29(1): 103-110.

26) Wimalawansa SJ, Razzaque MS, Al-Daghri NM. 2018. Calcium and vitamin D in human health: Hype or real? J Steroid Biochem Mol Biol 180: 4-14.

27) Holick MF, Biancuzzo RM, Chen TC, Klein EK, Young A, Bibuld D, Reitz R, Salameh W, Ameri A, Tannenbaum AD. 2008. Vitamin D2 is as effective as vitamin D3 in maintaining circulating concentrations of 25hydroxyvitamin D. J Clin Endocrinol Metab 93(3): 677681.

28) Charoenngam N, Shirvani A, Holick MF. 2019. The ongoing D-lemma of vitamin D supplementation for nonskeletal health and bone health. Curr Opin Endocrinol Diabetes Obes 26(6): 301-305.

29) Holick MF. 2018. The death D-fying vitamin. Mayo Clin Proc 93(6): 679-681.

30) Dudenkov DV, Mara KC, Petterson TM, Maxson JA, Thacher TD. 2018. Serum 25-hydroxyvitamin D values and risk of all-cause and cause-specific mortality: A population-based cohort study. Mayo Clin Proc 93(6): 721-730.

31) Maghbooli Z, Sahraian MA, Ebrahimi M, Pazoki M, Kafan S, Tabriz HM, Hadadi A, Montazeri M, Nasiri M, Shirvani A, Holick MF. 2020. Vitamin D sufficiency, a serum 25-hydroxyvitamin D at least $30 \mathrm{ng} / \mathrm{mL}$ reduced risk for adverse clinical outcomes in patients with COVID-19 infection. PLoS One 15(9): e0239799.

32) Autier P, Gandini S, Mullie P. 2012. A systematic review: influence of vitamin D supplementation on serum 25hydroxyvitamin D concentration. J Clin Endocrinol Metab 97(8): 2606-2613.

33) Chung M, Lee J, Terasawa T, Lau J, Trikalinos TA. 2011. Vitamin D with or without calcium supplementation for prevention of cancer and fractures: an updated metaanalysis for the U.S. Preventive Services Task Force. Ann Intern Med 155(12): 827-838.

34) Holick MF, Binkley NC, Bischoff-Ferrari HA, Gordon CM, Hanley DA, Heaney RP, Murad MH, Weaver CM; Endocrine Society. 2011. Evaluation, treatment, and prevention of vitamin D deficiency: an Endocrine Society clinical practice guideline. J Clin Endocrinol Metab 96(7): 1911-1930.

35) Veugelers PJ, Pham TM, Ekwaru JP. 2015. Optimal vitamin D supplementation doses that minimize the risk for both low and high serum 25-hydroxyvitamin D concentrations in the general population. Nutrients $\mathbf{7}(12)$ : 10189-10208.

36) Lips P, van Schoor NM, de Jongh RT. 2014. Diet, sun, and lifestyle as determinants of vitamin D status. Ann NY Acad Sci 1317: 92-98. 